ISSN 0258-7122 (Print), 2408-8293 (Online)

Bangladesh J. Agril. Res. 41(2): 297-310, June 2016

\title{
EFFECT OF STORAGE DURATION ON THE STORED PUPAE OF PARASITOID Bracon hebetor (Say) AND ITS IMPACT ON PARASITOID QUALITY
}

\author{
M. S. ALAM ${ }^{1}$, M. Z. ALAM ${ }^{2}$, S. N. ALAM ${ }^{3}$ \\ M. R. U. MIAH ${ }^{4}$ AND M. I. H. MIAN ${ }^{5}$
}

\begin{abstract}
The ecto-endo larval parasitoid, Bracon hebetor (Say) is an important biocontrol agent. Effective storage methods for $B$. hebetor are essential for raising its success as a commercial bio-control agent against lepidopteran pests. The study was undertaken to determine the effect of storage duration on the pupae of Bracon hebetor in terms of pupal survival, adult emergence, percent parasitism, female and male longevity, female fecundity and sex ratio. Three to four days old pupae were stored for $0,1,2,3,4,5,6,7$ and 8 weeks at $4 \pm 1^{\circ} \mathrm{C}$. The ranges of time for adult emergence from stored pupae, production of total adult, survivability of pupae, parasitism of host larvae by the parasitoid, longevity of adult female and male and fecundity were 63.0 -7.5 days, 6.8-43.8/50 host larvae, $13.0-99.5 \%, 0.0-97.5 \%, 0.00-20.75$ days, 0.00-17.25 days and 0.00$73.00 / 50$ female, respectively. The time of adult emergence and mortality of pupae increased but total number of adult emergence, survivability of pupae, longevity of adult female and male decreased gradually with the progress of storage period of $B$. hebetor pupae. The prevalence of male was always higher than that of female. Therefore, short-term storage of $B$. hebetor pupae could be stored for up to 4 weeks without disturbing the functioning of the parasitoid. It is important for sustaining and accumulating large numbers of parasitoids in mass rearing programs and subsequent use of field application.
\end{abstract}

Keywords: Cold storage, pupae, Bracon hebetor; biological control.

\section{Introduction}

The ecto-endo larval parasitoid, Bracon hebetor (Hymenoptera: Braconidae) is deemed as an important bio-control agent of different lepidopteran pests invading warehouse and field (Uwais et al., 2006; Imam et al., 2007; Garba and Gaoh, 2008). It is broadly used in studies of host parasitoid relations and biological control due to its high propagative rate, short cohort time and extensive range of host species (Asfaq et al., 2011).

\footnotetext{
${ }^{1}$ Senior Scientific Officer, Vertebrate Pest Division, Bangladesh Agricultural Research Institute (BARI), Gazipur, ${ }^{2 \& 4}$ Professor, Department of Entomology, Bangabandhu Sheikh Mujibur Rahman Agricultural University (BSMRAU), Gazipur, ${ }^{3}$ Chief Scientific Officer and Head, Entomology Division, BARI, Gazipur, ${ }^{5}$ Professor, Department of Plant Pathology, BSMRAU, Gazipur, Bangladesh.
} 
The mass production of $B$. hebetor is restricted by the accessibility of host larvae. Moreover, host larvae parasitized by $B$. hebetor may be oversupplied and rejected when demand for parasitoids is low. As a result, finding effective storage methods for $B$. hebetor is necessary for increasing its success as a commercial biocontrol agent against lepidopteran pests. One of the major difficulties to the use of biological control agent as insect natural enemies is the breakdown to obtain adequate numbers required for release (Coudron et al., 2007). As a result, the enhancement of storage methods for biocontrol agents is very important for efficient mass production of the parasitoid (Tezze and Botto, 2004; Greenberg et al., 1996; Leopold, 1998). Cold storage is regarded as an important tool for storage of mass reared biocontrol agents (Chen et al., 2011). For escalating the shelf-life of natural enemies and to make available a stable and enough number of parasitoids for biological control programs low temperature storage is an important technique. Storage at low temperature also permits coordinated field releases of natural enemies during the crucial stages of pest occurrences (Venkatesan et al., 2000; Colinet and Boivin, 2011).

Adults and pupae have been accounted to be the most cold-hardy stages of $B$. hebetor (Franqui Rivera, 1995; Carrillo et al., 2005). Very few studies have been done with cold storage on the performance of $B$. hebetor, and this study has focused on the adult stage (Al-Tememi and Ashfaq, 2005). Storage of $B$. hebetor pupae at $6^{\circ} \mathrm{C}$ for 3 weeks resulted in an $82.7 \%$ decrease in adult emergence (Al-Tememi and Ashfaq, 2005). According to Chen et al. (2011) more than 30 days of storage decreases parental parasitism but had no effect on parasitism of the $F_{1}$ generation. Parental durability and fecundity reduced after more than 20 days of storage. The present study was undertaken to determine the effect of storage duration of pupae of $B$. hebetor at $4 \pm 1{ }^{\circ} \mathrm{C}$ on some biological parameters of adults and their progeny.

\section{Materials and Method}

\section{Collection of host insect wax moth (Galleria mellonella)}

The target host used in the study was Galleria mellonella (L.) (Lepidoptera: Pyralidae). It was originally collected from infested bee-hive and maintained on artificial diet in IPM laboratory, Entomology Division, Bangladesh Agricultural Research Institute, Gazipur, Bangladesh. The dark bee wax was sterilized by boiling and put in $1000 \mathrm{ml}$ glass jars. One hundred larvae of wax moth were kept in the glass jar. The adults of $G$. mallonella coming out from the wax in the jar were allowed to mate and egg laying. After egg hatching, the $1^{\text {st }}$ and $2^{\text {nd }}$ instar larvae of wax moth were released in jars containing artificial diet. The diet was prepared by mixing wheat flour, maize crush, milk, sugar, animal fat, wax and yeast and autoclaved at $120{ }^{\circ} \mathrm{C}$ under $1.0 \mathrm{Kg} \mathrm{cm}^{-2}$ pressure for 70 minutes. Full grown final instar larvae were collected after 18 to 20 days and used as host for 
rearing of $B$. hebetor. The ambient temperature of the rearing room was $26.0 \pm$ $2^{\circ} \mathrm{C}$, relative humidity $70 \pm 5 \%$ and $12 \mathrm{~L}: 12 \mathrm{D}$ photoperiod.

\section{Collection of Bracon hebetor}

Bracon hebetor was obtained from IPM laboratory, Entomology Division, BARI, Gazipur. It is used for many years for the biocontrol of lepidopteran pest and maintained on honey and last instar larvae of G. mellonella. Adult parasitoids were introduced into plastic jars $(1000 \mathrm{ml})$ containing last instar larvae of $G$. mellonella and a cotton ball soaked with honey. Mouth of the jar was covered with black cloth. Environmental conditions of the rearing were the same as used for rearing the host G. mellonella. To obtain newly emerged parasitoids, 3 females and 2 males of $B$. hebetor adults were released into a plastic jar containing $10 \mathrm{G}$. mellonella final instars larvae and the whole container was covered with black cloth and kept for 3-4 days. To assess the parasitic activity of the $B$. hebetor in low temperature, 3 to 4 days old parasitoid pupae were isolated from the laboratory culture and placed in plastic jars. Before placing of pupae, the jars were sterilized in an electric oven. Each jar received 50 parasitoid pupae. The jars were stored in a refrigerator at $4 \pm 1^{\circ} \mathrm{C}$ and $60-70 \% \mathrm{RH}$ for $1,2,3,4,5,6$, 7 and 8 weeks. Four jars (replications) were used for each treatment (storage period). Another four jars containing pupae of the parasitoid were stored at room temperature, which served as a control.

\section{Effect of cold storage on Bracon hebetor parental generation}

At the end of each storage period, the pupae were moved to a chamber having ambient temperature of $26 \pm 2{ }^{\circ} \mathrm{C}$ and $\mathrm{RH} 70 \pm 5 \%$. Data on pupal survivability (adults emerged per parasitized pupae), time of adult emergence (days between the end of cold storage of the pupae until emergence of adult parasitoid) and sex ratio (adult females per total individuals) were recorded. The effects of storage time in low temperature storage on parasitism, longevity and fecundity of the parental generation were noted. To examine the capability and performance of a female $B$. hebetor after low temperature storage, a female and a male were taken where emerged from each cold storage period. Both male and were placed in a plastic jar $(1000 \mathrm{ml})$ having corrugated sheet containing 10 released larvae of $G$. mellonella and a cotton ball dipped in honey. The mouth of the jars was covered with black cloth and the whole container was covered with black cloth. The wax moth larvae and $B$. hebetor were placed on a rack for 8-10 days for parasitization, egg laying, pupation and adult emergence of $B$. hebetor. Data were expressed as $\%$ parasitism, fecundity and total adult progeny and sex ratio for each storage duration. Each treatment was replicated four times using completely randomized Design. There was also a control treatment maintaining room temperature $26 \pm 2$ ${ }^{\circ} \mathrm{C}$ and $70 \pm 5 \% \mathrm{RH}$. 


\section{Statistical analysis}

Data were analyzed using SPSS 16 software and presented in mean \pm SE. Mean time of developmental, parasitism, longevity of adult, sex ratio, and daily and lifetime fecundity of the parasitoid were evaluated using one-way Analysis of Variance (ANOVA). Differences among the means were evaluated using Turkey's Honestly significant differences test. Before performing ANOVA, \% parasitism, survival and mortality were transformed using arcsine transformation.

\section{Results and Discussion}

\section{Effect of cold storage on $B$. hebetor parental generation}

The minimum time of 5.3 days was required for adult's emergence from pupae under control. The time increased to 6.3-7.5 days when the pupae were stored in a refrigerator for 1 to 8 weeks. The increase in emergence time was significant over control when the pupae were stored for 2-8 weeks. The differences in adult emergence time from pupae stored for 2-8 weeks were not significant (Fig. 1).

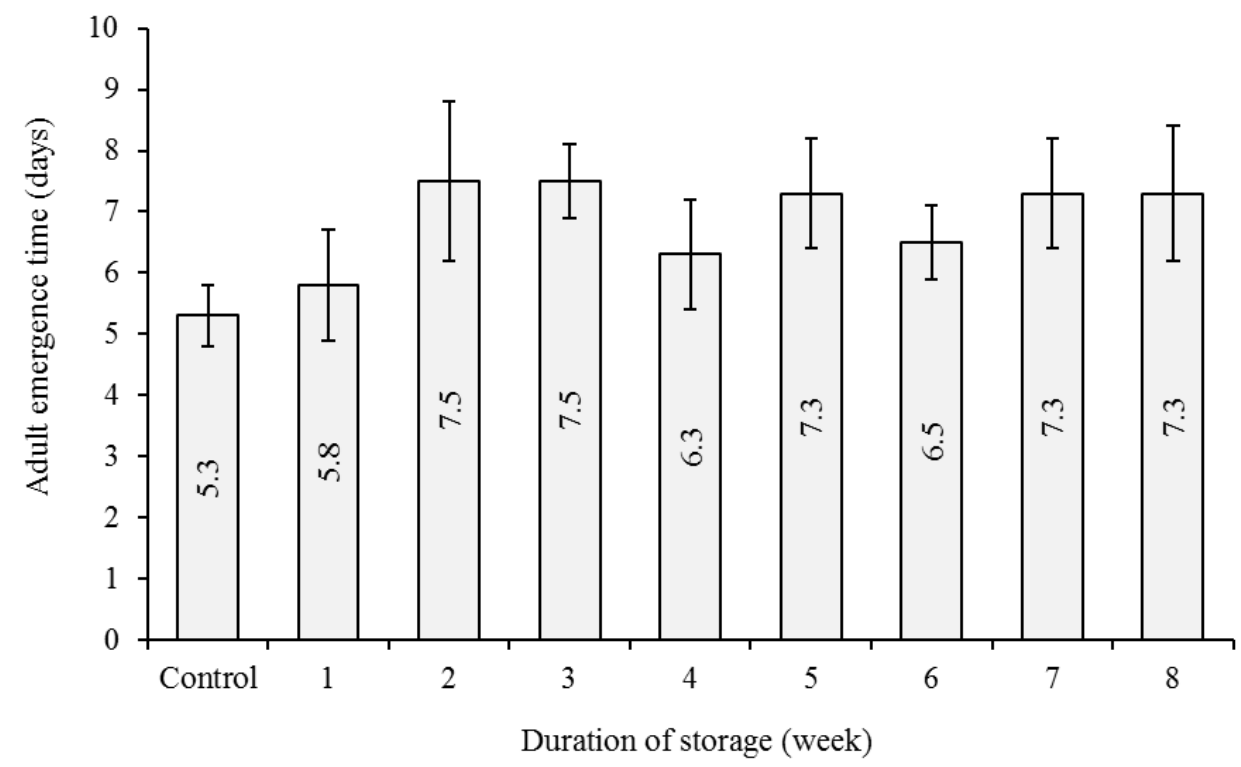

Fig. 1. Adult emergence time (days) of Bracon hebetor from pupae stored at $4^{\circ} \mathrm{C}$ in a refrigerator for 1-8 weeks. Vertical line in the bar denotes the standerd error of mean.

Significantly the highest number of adult (49.8) was emerged in control. Adult emergence decreased $43.8-6.850^{-1}$ pupae when the pupae were stored for 1-8 weeks. The lowest number of adults emergence was recorded from pupae stored for 8 weeks (Fig. 2). 


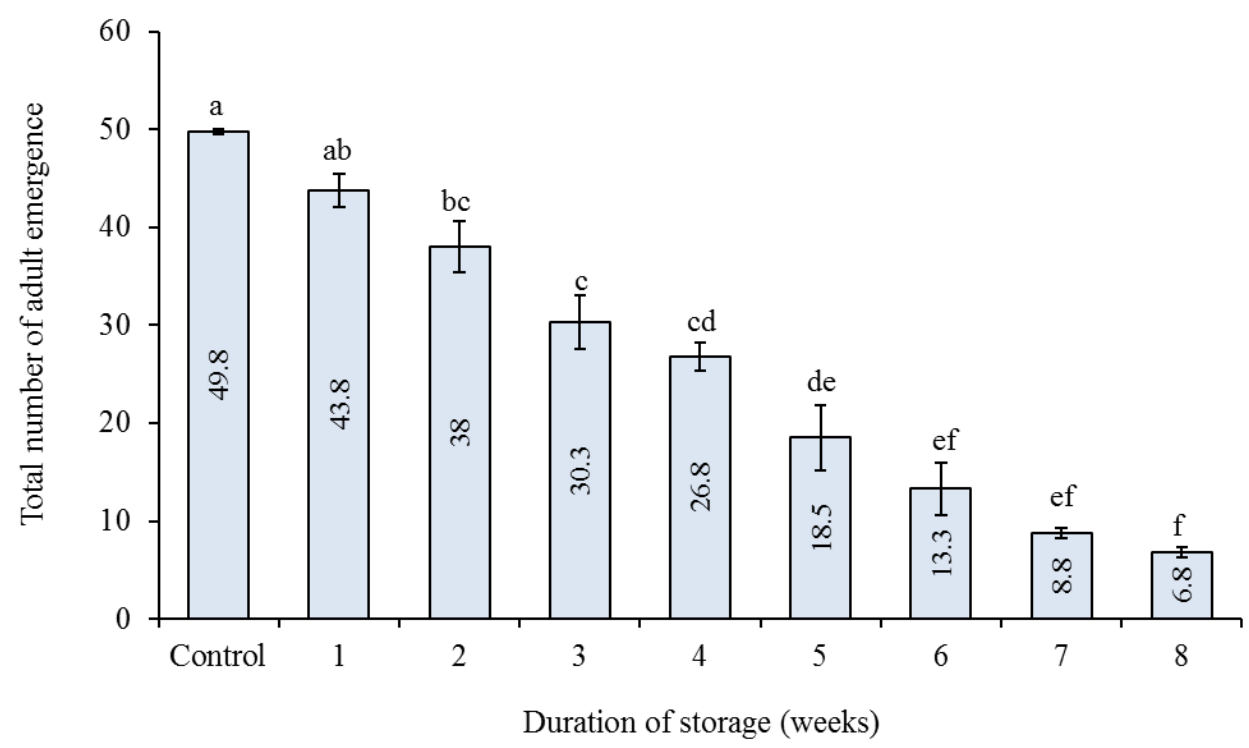

Fig. 2. Total number of adult emergence from pupae of Bracon hebetor stored at $4^{\circ} \mathrm{C}$ in a refrigerator for 1 to 8 weeks. Vertical line in the bar denotes the standerd error of mean. Bars indicating the same letter are not significantly different by Tukey's HSD test.

Significantly the highest percentage of survival $(99.5 \%)$ of $B$. hebetor pupae was recorded in control. The survival rates were significant differences. The lowest survival rate (13.0\%) was recorded after 8 weeks of storage (Fig. 3).

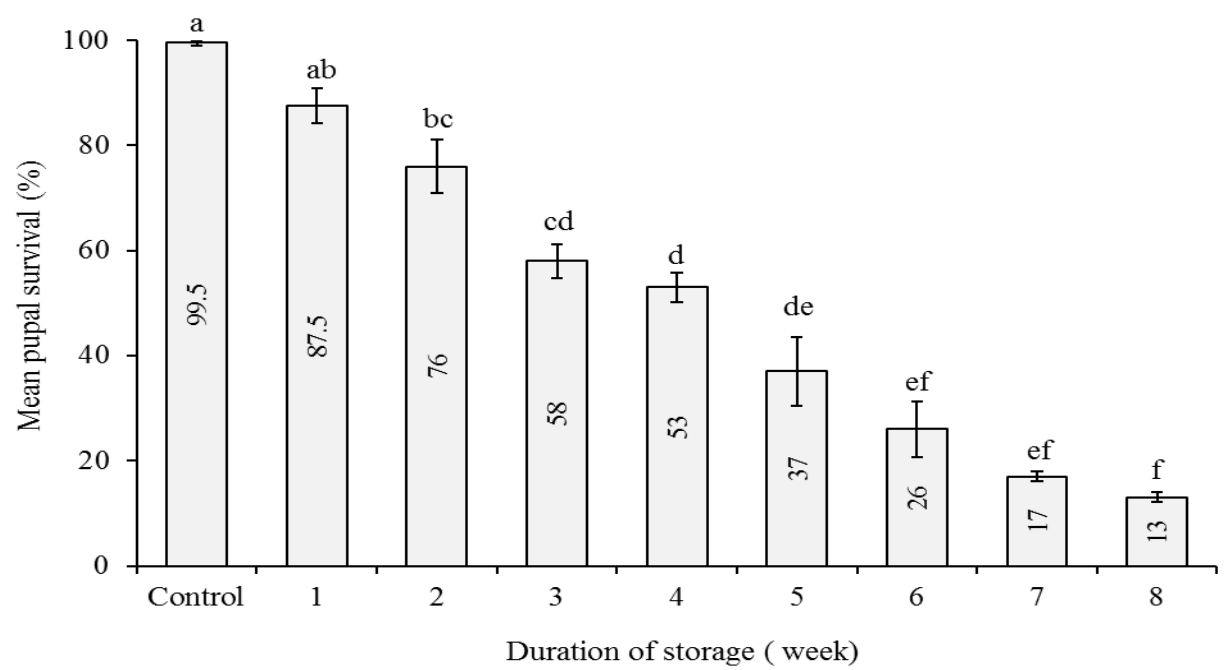

Fig. 3. Mean survival percentage of Bracon hebetor pupae stored at $4^{\circ} \mathrm{C}$ for $1-8$ weeks. Vertical line in the bar denotes the standerd error of mean. Bars followed by the same letter are not significantly different by Tukey's HSD test. 


\section{Parasitism efficacy of Bracon hebetor after 1-8 weeks of storage}

Percentage parasitism in 1 and 2 weeks were $97.5,97.5$ and $95.0 \%$, which were statistically similar but significantly higher compared to other period of storage. After 2 weeks, the parasitism decreased gradually. The lowest parasitism was found after 6 weeks, which was statistically similar to 5 weeks of storage (Fig. 4). The pupae of $B$. hebetor stored for more than 6 weeks failed to parasitize the host larvae (Fig. 4).

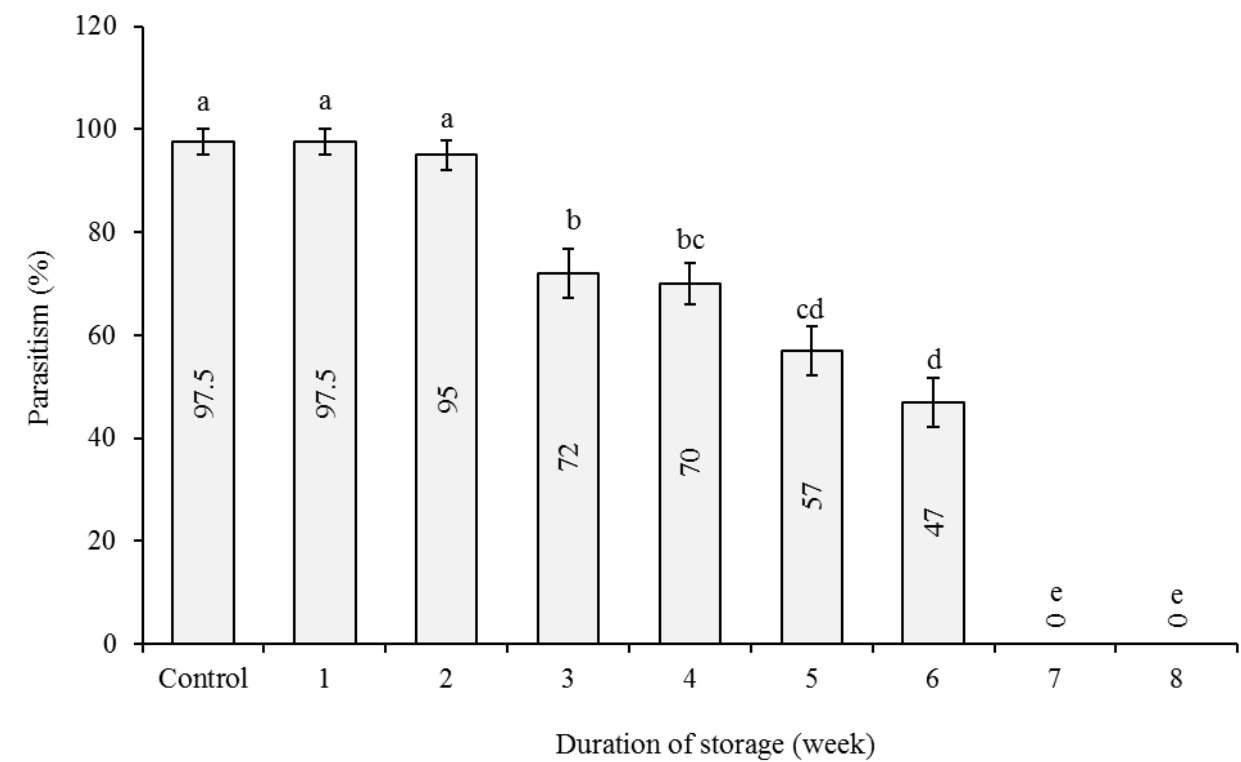

Fig. 4. Percentage of parasitized host (G. mellonella) larvae per female of Bracon hebetor emerged from pupae stored at $4^{\circ} \mathrm{C}$ for $1-8$ weeks. Vertical line in the bar denotes the standerd error of mean. Bars indicating the same letter are not significantly different by Tukey's HSD test.

The highest longevity of parent female was recorded from control, which was statistically similar to the females emerged from pupae stored for 1 and 2 weeks. The lowest longevity was found after 6 weeks of storage. The maximum survivability was found in parent male emerged from pupae stored at room temperature (control) followed by pupae stored at $4^{\circ} \mathrm{C}$ for $1,2,3$ and 4 weeks (Fig. 5). The lowest longevity of $F_{1}$ male was recorded from pupae stored for 6 weeks followed by 5 weeks of storage (Fig. 6). Both $F_{1}$ female and male were recorded when the pupae were stored for 7 weeks or longer duration because no parasitism occurred. It is evident that the longevity of parents was generally lower than that of their $\mathrm{F}_{1}$ offspring in both the cases of male and female. 


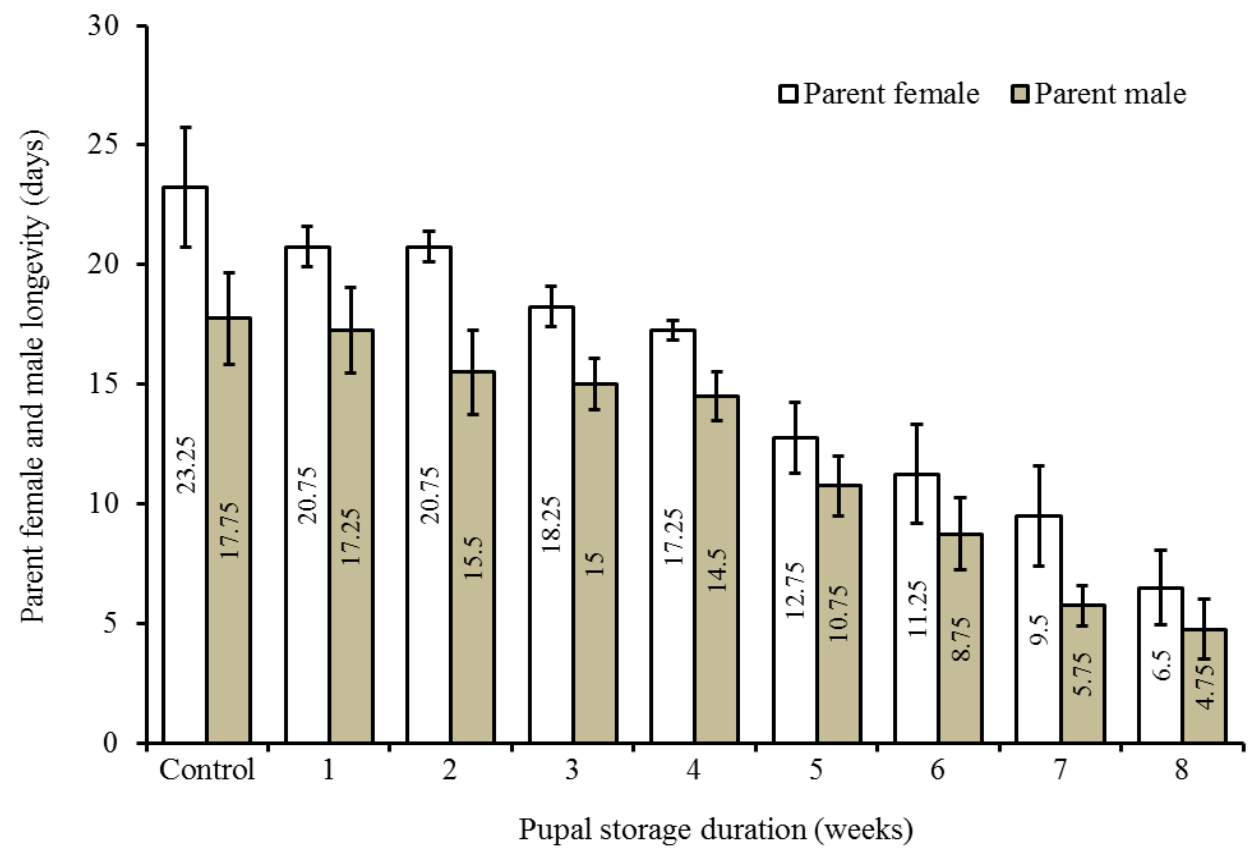

Fig. 5. Longevity of female and male parents emerged from pupae of Bracon hebetor tored at $4^{\circ} \mathrm{C}$ for $1-8$ weeks. Vertical line in the bar denotes the standerd error of mean.

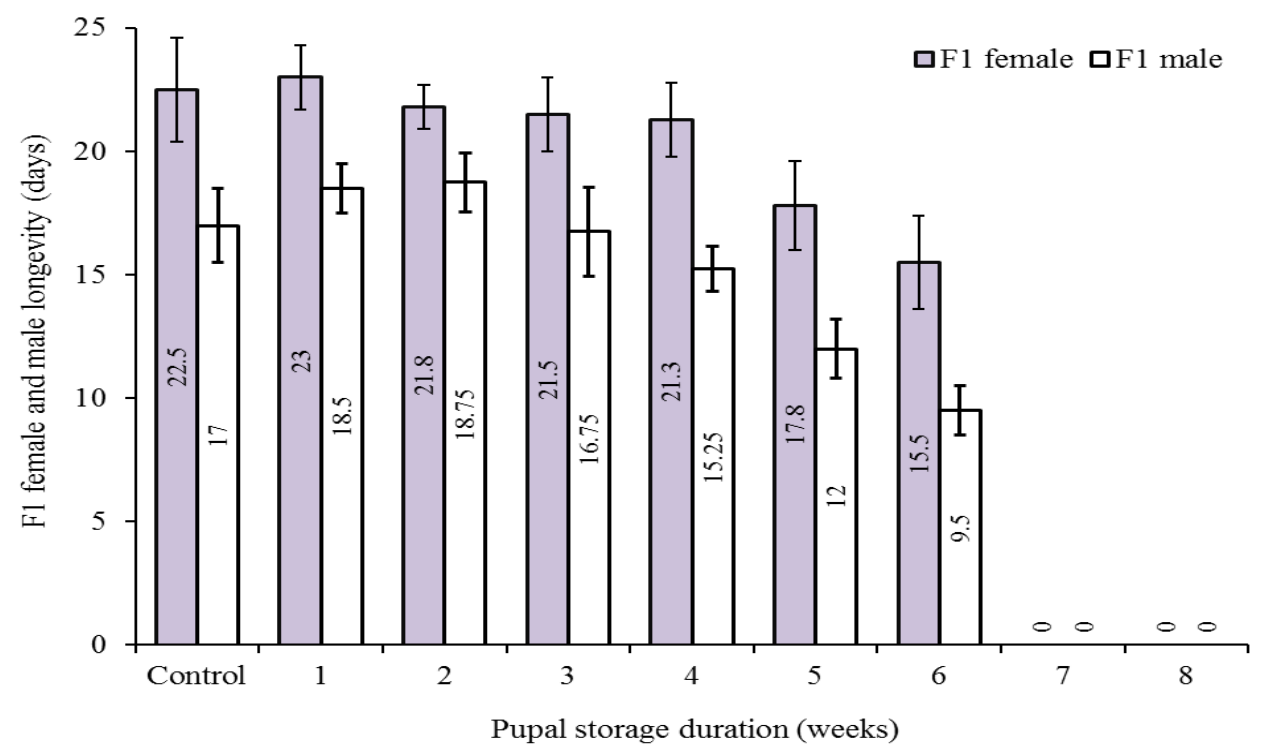

Fig. 6. Longevity of $F_{1}$ female and male parents emerged from pupae of Bracon hebetor at $4^{\circ} \mathrm{C}$ for 1-8 weeks. Vertical line in the bar denotes the standerd error of mean. 


\section{Fecundity of parents}

The highest fecundity (76.3 adults female ${ }^{-1}$ ) was recorded from pupae stored under room conditions, which was not significantly different from that of parents emerged from pupae stored for 1 week at $4^{\circ} \mathrm{C}$. The fecundity of parents emerged from pupae stored at $4^{\circ} \mathrm{C}$ for 2,3 and 4 weeks was different. The lowest fecundity was observed after 6 week of storage $\left(8.5\right.$ adults female $\left.{ }^{-1}\right)$ followed by the storage duration of 5 weeks (Fig. 7).

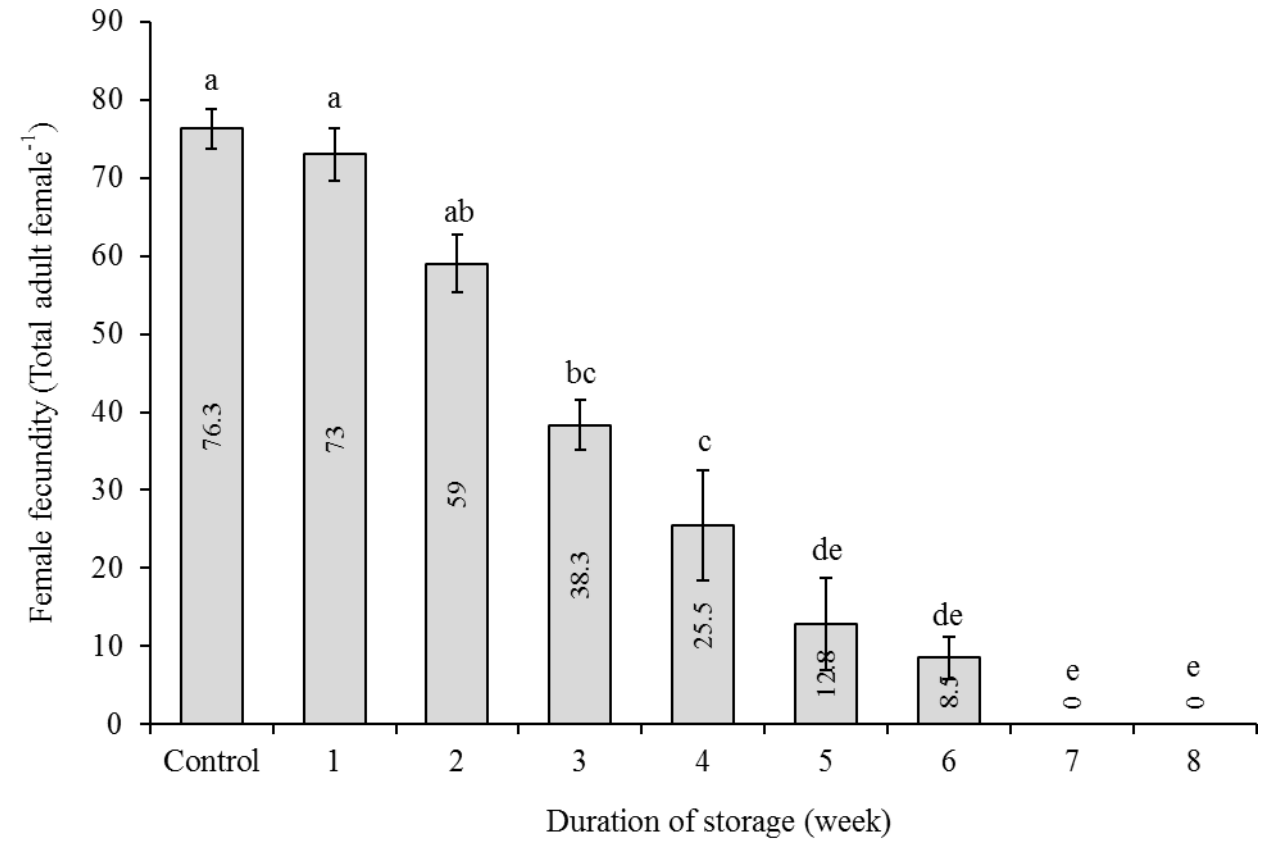

Fig. 7. Fecundity (total adult female ${ }^{-1}$ ) of Bracon hebetor parents emerged from pupae stored at $4^{\circ} \mathrm{C}$ for $1-8$ weeks. Vertical line in the bar denotes the standerd error of mean. Bars indicating the same letter are not significantly different by Tukey's HSD test.

\section{Sex ratio of parent and $F_{1}$ progeny}

The percentages of female and male emerged from pupae stored under control and at $4^{\circ} \mathrm{C}$ for $1-8$ weeks ranged $26.97-40.43 \%$ with a mean of $40.44 \%$ and $51.40-59.57 \%$ with a mean of $59.57 \%$, respectively. After each storage duration in refrigerator as well as under control, the prevalence of male was higher than that of female (Fig. 8). Like parent female and male sex ratio (\%), the prevalence of male was higher compared to $\mathrm{F} 1$ female. The percentage of $\mathrm{F}_{1}$ female ranged $26.97-46.36 \%$ with a mean of $40.98 \%$ and that of male ranged $51.71-63.61 \%$ with mean $43.96 \%$ (Fig. 9). 


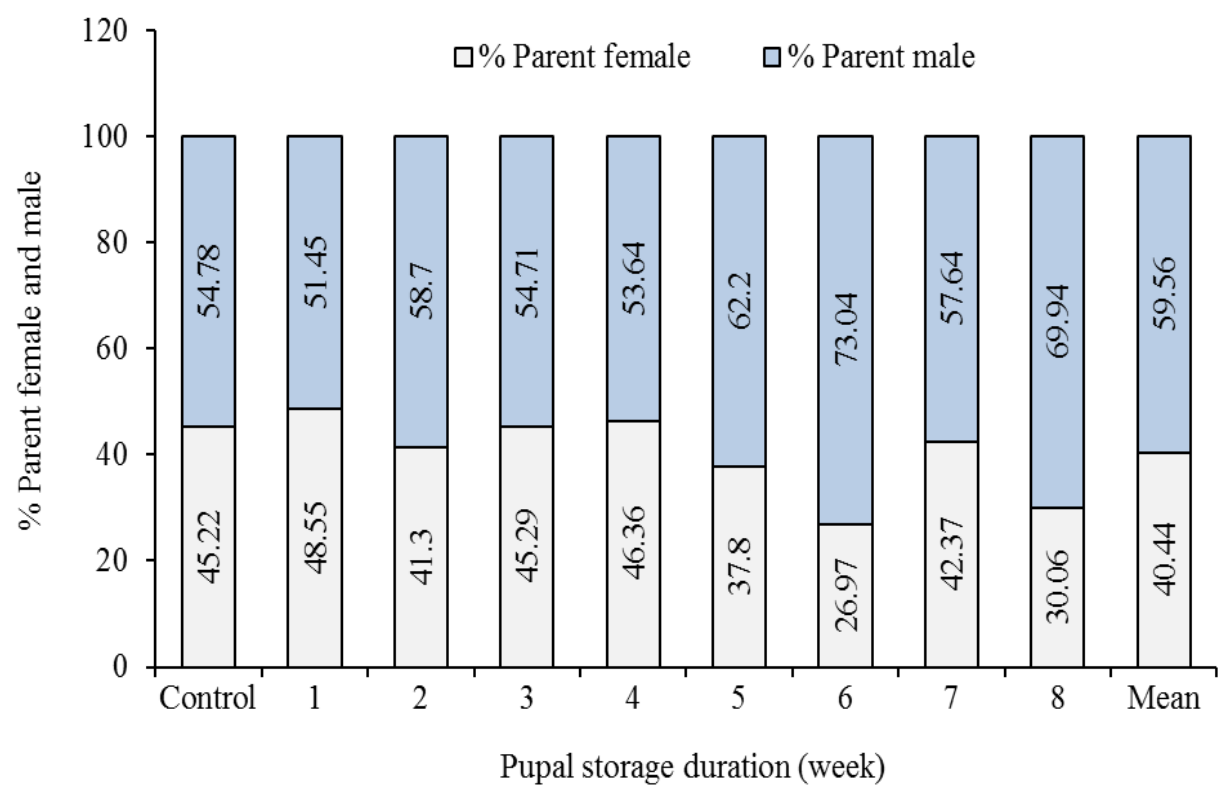

Fig. 8. Percentage of parent adult female and male emerged from pupae of Bracon hebetor stored at $4^{\circ} \mathrm{C}$ for 1-8 weeks.

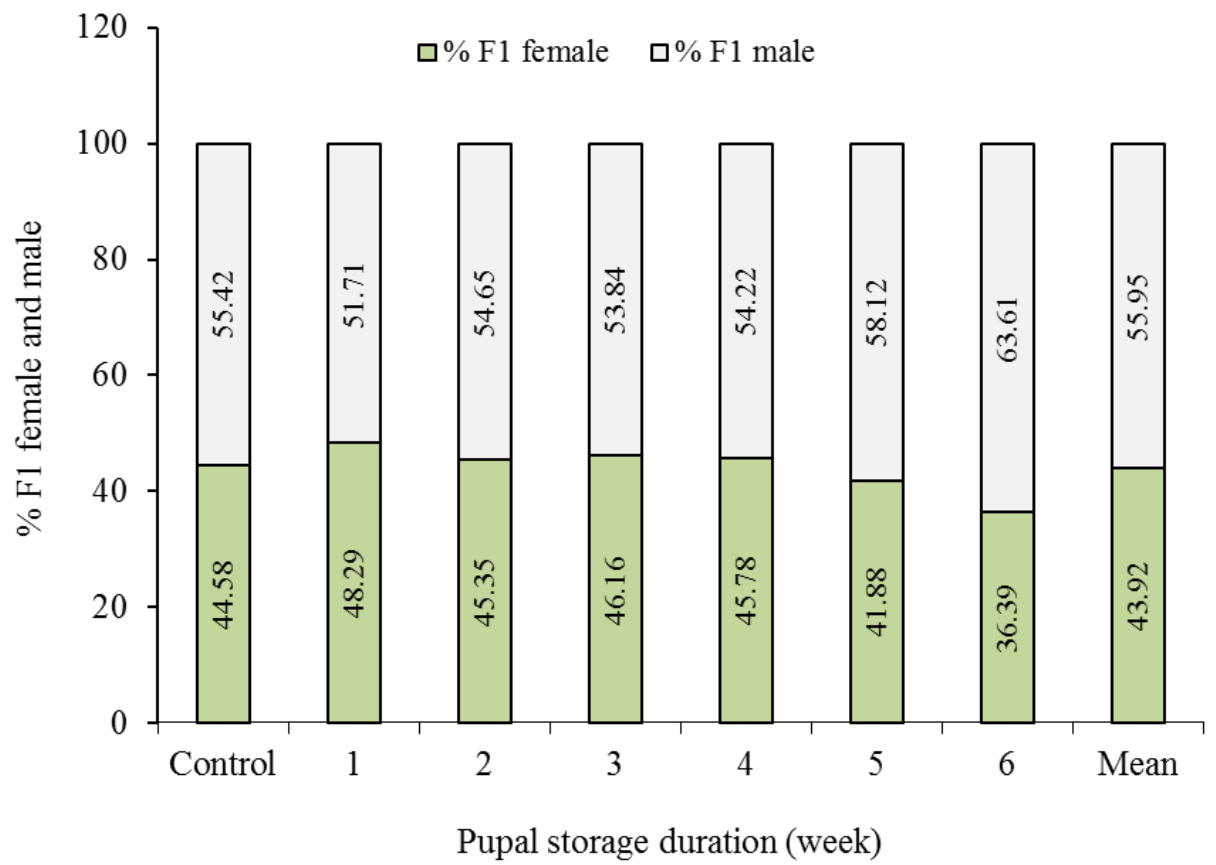

Fig. 9. Percentage of $F_{1}$ female and male of Bracon hebetor emerged from pupae stored under room conditions and at $4^{\circ} \mathrm{C}$ for 1 to 6 weeks. 
Due to storage of $B$. hebetor pupae in a refrigerator at $4^{\circ} \mathrm{C}$ for $1-8$ weeks, the time of adult emergence and mortality of pupae increased but total number of adult emergence, survivability of pupae, longevity of adult female and male decreased gradually with the progress of storage period of $B$. hebetor pupae of the parasitoid. The prevalence of male is always higher compared to female. Similar findings have been reported by many other investigators (Al-Ramahi and Ali, 1983; Ahmed et al., 1985). Adult emergence time is vital to realize the time needed for adult coming out after removing pupae from cool storage, particularly in order to synchronize adult emergence of parasitoid and availability of mature larvae of the pest in the field. Cold temperature prevented the embryonic growth of Trichogramma nerudai pupae (Tezze and Botto, 2004). In addition, in the existing observation the adult emergence time for cold stored pupae was 1 day higher than in the control group. This dissimilarity might be due to putting off in returning back to standard metabolic conditions at exposure after being cold stored for longer period. It is a correct statement that organisms placed at low, above zero temperatures have seasonal restructuring of metabolism as a way of cold-hardiness (Danks, 1978).

Mortality denotes the overall result of extended cold exposure. Moreover to cool damage, parasitoids stored as undeveloped may not have adequate energy to complete their growth and/or to come forward. In some solitary species, dissection of non-emerged parasitoids after cold storage has shown that mortality occurred mainly after metamorphosis in pharate adults (Colinet et al., 2006; Colinet and Hance, 2009). There have been reported that the completely developed adults dying during the exclusion process (Levie et al., 2005; Luczynski et al., 2007). The procedure of coming out is energy-consuming as it needs strong muscle convulsion (Yocum et al., 1994) and chilling is known to induce muscular nonfunctions (Kelty et al., 1996). Emergence of pharate adults fail after cold storage due to lack of energy along with muscular perturbation. In another species, mortality withstands generally during pupation (Chen and Leopold, 2007).

Longevity of parents and their $F_{1}$ offspring declined with increase in cold storage period. Because living organisms have limited resources which are spent on growth, reproduction, and maintenance (Green and Rothstein, 1991), a possible explanation for the decline in longevity may be that increasingly larger amounts of resources are depleted by maintenance during longer periods of cold storage at $4^{\circ} \mathrm{C}$ thereby resulting in reduced performance and survival (Salt, 1961). In addition, accumulation of toxic metabolites also causes death or reduced fitness after prolonged exposures to cold (Storey and Storey, 1988).

Fecundity of parents declined with increase in cold storage period. Decline in fecundity with increase in cold storage period is probably due to the aforementioned reasons. The reproductive organs are particularly vulnerable to 
low temperature effects (Denlinger and Lee, 1998). In Euchalcidia caryobori (Hanna), low temperature may either cause retardation of egg maturation or, in its extremes, malformation of reproductive organs in both sexes (Hanna, 1935). Numerous observations have been made on the reduction of parasitoid fecundity after cold storage. Like most of the traits affected by cold storage, the fecundity cost is generally proportional to both the temperature and the duration of exposure (Venkatesan et al., 2000; Al-Tememi and Ashfaq, 2005).

Our present results demonstrated that the low temperature storage of the maternal age group did not seem to impact $F_{1}$ generation characters when cold storage periods were shorter than 35 days. This probably might be due to action of cold storage for the maternal generation only. The procedure for overtaking maternal effects of chilling injury to the $F_{1}$ generation is unidentified. One possible explanation is the property of eggs laid by females stored for a long time may decline. An alternative grounds for reduced fitness of the $F_{1}$ progeny might have been due to maternal aging (Hercus and Hoffmann, 2000; Opit and Throne, 2007).

Effect of low temperatures recurrently deform insect sex ratios (Denlinger and Lee, 1998). Hymenopteran parasitoids typically have a haplodiploid sexdetermination system, as their females are able to decide the sex of their generation by regulating fertilization (Flanders, 1956). Deformation of sex ratio may appear from diverse origins. First alteration of the ratio of fertilized eggs oviposited (i.e. primary sex ratio) may be monitored following alteration of the female reproductive approach or the incapability of males to mate or inability to produce viable sperm after a cold treatment (Lacoume et al., 2007). Sex ratio deformations can also result from a discrepancy of mortality between sexes when undeveloped stages are exposed to cold (i.e., secondary sex ratio). The results of the present study are similar to the findings of other studies (Ashfaq et al., 2011; Shawkit et al., 2000). They found that the ratio of adultemergence from the cold-stored pupae of this parasitoid decreased with the increase of storage period. Findings denoted that the sex ratio of $B$. hebetor was 1:1.3 (F:M) (Al-Ramahi and Ali, 1983). Another study indicated that female: male sex ratio was 1:3.9 (Ahmed et al., 1985). Male biased sex ratio was obtained in the present which explained that the male eggs hatched before than the female eggs, and the male larvae would have a better survivability due to sufficient food (Benson, 1973).

Our findings reveal that $B$. hebetor can be stored up to 4 weeks without affecting the performance of the parasitoid. However, short-term storage of $B$. hebetor pupae can be used for regulating and gathering huge numbers of parasitoids in mass production programs. 


\section{References}

Ahmed, M. S. H., S. K. Al-Maliky, A. A. Al-Taweel, N. F. Jabo and Z. S. Al-Hakkak. 1985. Effects of three temperature regimes on rearing and biological activities of Bracon hebetor (Say) (Hymenoptera: Braconidae). J. Stored. Prod. Res. 21(2): 65-68.

Al-Ramahi, R.S.H. and M.H. Ali. 1983. Life span of Bracon hebetor (Say) (Hymenoptera: Braconidae). Bull. Soc. Ent. Egypt 4(1): 22-29.

Al-Tememi, N.K. and M. Ashfaq. 2005. Effect of low temperature storage on the fecundity and parasitizing efficacy of Bracon hebetor (Say). J. Agrl. Res. 43: 155-160.

Ashfaq. M., R.R. Khan and M.A. Farooq. 2011. Refinement of rearing technique of a potent larval parasitoid Bracon hebetor (Say), (Braconidae: Hymenoptera). Proc. Pakistan Aca. Sci. 48 (2): 83-88.

Benson, J.F. 1973. The biology of lepidoptera infesting stored products, with special reference to population dynamics. Biol. Rev. 48: 1-26.

Carrillo, M.A., G.E. Heimpel, R.D. Moon, C.A. Cannon and W.D. Hutchison. 2005. Cold hardiness of Habrobracon hebetor (Say) (Hymenoptera: Braconidae), a parasitoid of pyralid moths. J. Insect Physiol. 51:759-768.

Chen, H, G.P. Opit, P. Sheng and H. Zhang. 2011. Maternal and progeny quality of Habrobracon hebetor (Say) (Hymenoptera: Braconidae) after cold storage. Biol. Contrl. 58: 255-261.

Chen, W.L., R.A. Leopold. 2007. Progeny quality of Gonatocerus ashmeadi (Hymenoptera: Mymaridae) reared on stored eggs of Homalodisca coagulata (Hemiptera: Cicadellidae). J. Econ. Entomol. 100: 685-694.

Colinet, H. and G. Boivin. 2011. Insect parasitoids in cold storage: A comprehensive review of factors of variability and consequences. Biol. Contrl. 58: 83-95.

Colinet, H., T. Hance and P. Vernon. 2006. Water relations, fat reserves, survival, and longevity of a cold-exposed parasitic wasp Aphidius colemani (Hymenoptera: Aphidiinae). Environ. Entomol. 35: 228-236.

Colinet, H. and T.H. Hance, 2009. Male reproductive potential of Aphidius colemani (Hymenoptera: Aphidiinae) exposed to constant or fluctuating thermal regimes. Environ. Entomol. 38: 242-249.

Coudron, T.A., M.R. Ellersieck and K.S Shelby. 2007. Influence of diet on long-term cold storage of the predator Podisus maculiventris (Say) (Heteroptera: Pentatomidae). Biol. Contr. 42: 186-195.

Danks, H. 1978. Modes of seasonal adaptation in the insects, in winter survival. Can. Entomol. 110 (11): 1167-1205.

Denlinger, D.L. and R.E.Jr. Lee. 1998. Physiology of cold sensitivity. In: Temperature Sensitivity in Insects and Application in Integrated Pest Management. eds. by Hallman, G.J and Denlinger D.L. Westview Press, Boulder. 55-96 P.

Flanders, S.E. 1956. The mechanism of sex-ratio regulation in the parasitic hymenoptera. Insectes Sociaux 3: 325-334. 
Franqui Rivera, R.A. 1995. Behavioral patterns of seasonal field activity and cold tolerance in Bracon hebetor Say (Hymenoptera: Braconidae). Dissertation, University of Wisconsin-Madison.

Garba, M. and N.B. Gaoh. 2008. Use of Habrobracon hebetor in biological control of Heliocheilus albipunctella pearl millet head miner, Pp. 436-444. AFPP - 8eme Conference Internationale sur les Ravageurs en Agriculture, 22-23 Oct 2008. Montpellier SupAgro, France.

Green, W.C.H. and A. Rothstein. 1991. Trade-offs between growth and reproduction in female bison. Oecologia, 86: 521-527.

Greenberg, S.M., D.A. Nordlund and E.G. King. 1996. Mass production of Trichogramma spp.: experiences in the former Soviet Union, China, the United States and western Europe. Biocontrl News Inform. 17: 51-60.

Hanna, A.D. 1935. Fertility and tolerance of low temperature in Euchalcidia carybori Hanna (Hymenoptera: Chalcidinae). Bull. Entomol. Res. 26: 315-322.

Hercus, M.J. and A.A. Hoffmann. 2000. Maternal and grandmaternal age influence offspring fitness in Drosophila. Proc. Royal. Soc. Lond Ser. B. Biol. Sci. 267: 21052110.

Imam, M., A. Uwais, U. Namat, A. Akbar and T. Ahmat, 2007. Influence of Habrobracon hebetor on Helicoverpa armigera in southern Xinjiang. Nat. Enem. Insect. 29: 12- 15.

Kelty, J.D., K.A. Killian and R.E. Lee. 1996. Cold shock and rapid cold-hardening of pharate adult flesh flies (Sarcophaga crassipalpis): effects on behaviour and neuromuscular function following eclosion. Physiol. Entomol. 21: 283- 288.

Lacoume, S., C. Bressac and C. Chevrier. 2007. Sperm production and mating potential of males after a cold shock on pupae of the parasitoid wasp Dinarmus basalis (Hymenoptera: Pteromalidae). J. Insect. Physiol. 53: 1008-1015.

Leopold, R.A. 1998. Cold storage of insects for integrated pest management. In: Temperature Sensitivity in Insects and Application in Integrated Pest Management eds. by G. J. Hallman and D. L. Denlinger. Westview Press, Boulder. Pp. 235- 267.

Levie, A., P. Vernon and T. Hance. 2005. Consequences of acclimation on survival and reproductive capacities of cold-stored mummies of Aphidius rhopalosiphi (Hymenoptera: Aphidiinae). J. Econ. Entomol. 98: 704-708.

Luczynski, A., J.P. Nyrop and A. Shi. 2007. Influence of cold storage on pupal development and mortality during storage and on post-storage performance of Encarsia formosa and Eretmocerus eremicus (Hymenoptera: Aphelinidae). Biol. Contrl. 40: 107-117.

Opit, G.P. and J.E. Throne. 2007. Influence of maternal age on the fitness of progeny in the rice weevil, Sitophilus oryzae (Coleoptera: Curculionidae). Environ. Entomol. 36: 83-89.

Salt, R.W. 1961. Principles of insect cold-hardiness. Annu. Rev. Entomol. 6: 55-74. 
Shawkit, M.A., A.A. AI-Taweel and N.K. Al-Tememi. 2000. Effect of low temperature storage on the parasitizing efficacy of Bracon hebetor (Say), against dates moth larvae. Iraqi J. Agric. 5(3): 120-122.

Storey, K.B and J.M. Storey. 1988. Freeze tolerance in animals. Physiol. Rev. 68: 27-84.

Tezze, A.A. and E.N. Botto. 2004. Effect of cold storage on the quality of Trichogramma nerudai (Hymenoptera: Trichogrammatidae). Biol. Contrl. 30: 11-16.

Uwais, A, G.W. Chao, T. Ahemaiti and Y.X. Rong. 2006. Influence of different store condition on survive rate of adult wasps of reared Bracon hebetor say. Xinjiang Agril. Sci. 43: 109-112.

Venkatesan, T., S.P. Singh and S.K. Jalali. 2000. Effect of cold storage on cocoons of Goniozus nephantidis Muesebeck (Hymenoptera: Bethylidae) stored for varying periods at different temperature regimes. J. Entomol. Res. 24: 43-47.

Yocum, G.D., J. Zdárek, K.H. Joplin, R.E.Jr. Lee, D.C. Smith, K.D. Manter and D.L. Denlinger. 1994. Alteration of the eclosion rhythm and eclosion behavior in the flesh fly, Sarcophaga crassipalpis, by low and high temperature stress. J. Insect. Physiol. 40: 13-21. 